\title{
Integrasi Media MNC Dalam Meningkatkan Efisiensi Dan Kompetisi Pasar Bisnis Industri Penyiaran
}

\author{
Geofakta Razali, S. I. Kom, M. I. Kom \\ Universitas Bina Sarana Informatika, geofakta.gfr@bsi.ac.id
}

\begin{abstract}
ABSTRAK
Jurnal ini memberikan pemahaman tentang integrasi yang terjadi pada media khususnya MNC Group. Integrasi tersebut berhasil memberikan improvisasi pada efisiensi. Persaingan pasar industri media menjadi sebuat ketentuan yang menjadi landasan berpacunya media untuk menjadi sebuah holding dan saling menunjang dari sisi satu dan sisi lainnya. Penulis menggunakan teori SCP untuk melihat bagaimana struktur media, perilaku media, dan performancenya untuk mencapai sebuah konsep bisnis industri media yang sempurna. Fenomena konsentrasi media yang terjadi di Indonesia merupakan suatu kejadian yang benar-benar sedang terjadi dan menjadi perhatian oleh setiap orang. Penelitian ini menggunakan paradigma konstruktivis karena ingin menciptakan sebuah pemaknaan melalui pendekatan kualitatif. Indikatornya adalah menganalisa dan mengukur kompetisi dan efisiensi seuah media dengan hasil yang diharapkan melalui cara integrasi.
\end{abstract}

Kata Kunci: Integrasi, MNC Media Group, Efisiensi, Persaingan, Bisnis Penyiaran Media Industri

\section{ABSTRACT}

This thesis analyzes MNC Media at the viewside of media group in Indonesia with through the time and had raced into the largest integration media group in Southeast Asia. To analyze the efficiency and the competition that created by MNC Media Group, actually, researchers try to analyze based on the theory. That theory is Industrial Organization owned media Kranenburg. This theory explains how Structure, Conduct and Performance of a media become into a value chain to survive in the competition group media today we called is integration. There is also a research concept by adding strategy concepts of business broadcast media industry. The indicator used to measure and analyze the success rate occurred partly based on data media with the large revenue increase profit margins, many advertisers, competition audience share, and the company's efficiency.

Keywords: Integration, MNC Media Group, Efficiency, Competition, Industry Media Broadcasting Business

\section{PENDAHULUAN}

Aktivitas bisnis media penyiaran seperti kegiatan distribusi produk, operasional perusahaan, proses produksi, hingga persaingan media penyiaran dipenuhi dengan berbagai strategi yang dibuat untuk mewujudkan kegiatan ekonomi yang akan menciptakan efisiensi dan kemampuan berkompetisi dalam perkembangan perusahaan. Besarnya peluang pasar media penyiaran mendorong pengusaha dan pemilik media itu melebarkan sayapnya dengan memperbanyak eksistensi jenis media serupa atau lainnya.

Isu utama dalam dunia komunikasi moderen saat ini adalah pola kepemilikan serta praktik produksi dan distribusi 
produk media penyiaran yang terkonsentrasi pada kelompok-kelompok bisnis besar (Susanto, 2017).Kelompok bisnis tersebut kemudian melahirkan kompetisi pada pasar media penyiaran yang biasanya ditentukan oleh skala ekonomi.

Fenomena konsentrasi media yang terjadi di Indonesia merupakan suatu kejadian yang benar-benar sedang terjadi dan menjadi perhatian oleh setiap orang. Pengaruh pada kompleksnya industri media massa mengakibatkan adanya konsentrasi kepemilikan menjadi suatu proses yang tidak dapat dihindarkan oleh setiap pelaku industri media massa, khususnya penyiaran.

Integrasi pada dasarnya adalah kegiatan yang melibatkan alokasi sumber daya yang terbatas dengan penggunaan secara efisien untuk berkompetisi merebut pasar media penyiaran. Salah satu kelompok bisnis besar yang saat ini menjadi perhatian akan hal tersebut adalah MNC Media Group. Hal ini benar-benar memperlihatkan bahwa $M N C$ Group tidak main-main dalam mengelola manajemen strategis media, salah satunya melalui integrasi yang saat ini terdengar menjadi media dengan kerajaan integrasi media terbesar di Asia Tenggara.

MNC Media Group atau lebih khususnya PT Media Nusantara Citra, Tbk saat ini merupakan salah satu kerajaan media terbesar di Indonesia. Banyak unit media yang berada dibawah naungan $M N C$ Media Group diantaranya adalah RCTI, MNCTV, GlobalTV, INEWSTV, RDI Radio, Koran Seputar Indonesia, Okezone.com dan Indovision. Kepemimpinan media terbesar ini berada di bawah kekuasaan pengusaha besar Harry Tanusoedibjo (HT). Belakangan ini dengan jelas MNC Media Group mencoba menciptakan postioning dirinya sendiri dengan slogan "Southeast Asia's Largest and Most Integrated Media Group" yang mereperesentasikan bahwa saat ini bisnis roda perusahaan $M N C$ Group tidak hanya bergerak pada media, namun juga lini non media antara lain bisnis properti, dan berupa produk jasa keuangan terpadu seperti sekuritas, asuransi jiwa, asuransi kerugian, pembiayaan serta asset management yang juga ikut membantu operasional media penyiaran MNC Media Group itu sendiri.

Lewat beragam jaringan media sebagai sumber organik utama, MNC mampu menjangkau puluhan juta orang Indonesia. Bahkan, tidak hanya di negeri ini, MNC Media mengklaim dirinya sebagai kelompok media terbesar dan terintegrasi di Asia Tenggara.

Tujuan dari penelitian ini adalah melihat bagaimana proses industri bisnis media MNC Group berjalan dengan menggunakan strategi integrase untuk mencapai efisiensi.

\section{KAJIAN LITERATUR Teori Industrial Organization Media- Kranenburg}

Ada 3 konsep untuk aplikasi pendekatan ekonomi politik dalam industri komunikasi yang ditawarkan Moscow: a. Commodification (komodifikasi). Konsep ini mengacu pada pemanfaatan barang dan jasa yang dilihat dari kegunaannya kemudian ditransformasikan menjadi komoditi yang bernilai jual pasar. Bentuk komodifikasi dalam komuniikasi ada tiga macam:

1. intrinsinc commodification (komodifikasi intrinsik), extrinsinc commodification (komodifikasi ekstrinsik), dan cybernatic commodification (komodifikasi sibernatik).

2. Spatialization (spasialisasi) adalah proses untuk mengatasi hambatan ruang dan waktu dalm kehidupan sosial oleh perusahaan media dalam bentuk perluasan usaha seperti proses intregasi: integrasi horizontal, vertikal, dan internasionalisasi

3. . Structuration (strukturasi), yakni proses penggabungan human agency (agensi manusia) dengan proses perubahan sosial ke dalam 
analisis struktur. Karakteristik penting dari teori strukturisasi ialah kekuatan yang diberikan pada perubahan sosial, yang menggambarkan bagaimana struktur diproduksi dan direproduksi oleh agen manusia yang bertindak melalui medium strukturstruktur.

Ketiga siklus ekonomi politik media tersebut terpengaruh pada siklus hidup industri pasar media pasar media seperti berakhirnya media pada pasar kompetisi serta kemungkinan bertahannya dapat dilihat dari teori Industrial Organization Media milik Kranenburg dikutip dari (Rusadi, 2018) yaitu praktik industri media dipandang dari keorganisasian industri meliputi penentuan struktur pasar media, perilaku pasar, dan kinerja media. Struktur pasar meliputi kategori jumlah penjual dan pembeli apakah pasar monopoli, oligopoli atau pasar sempurna, keanekaragaman produk, hambatan memasuki pasar, struktur pembiayaan dan integrasi. Sedangkan perilaku pasar adalah penetapan harga, penelitian dan inovasi, perencanaan investasi dan taktik legal. Sedangkan elemen kinerja media dilihat dari efisiensi produk dan alokasi, perkembangan dan ekuitasnya.

Mc Connel dan Bruce (Fu, 2003) menyatakan analisa Structure-ConductPerformance (SPC) menyediakan suatu panduan untuk membuat formulasi penilaian empiris terhadap pelaksanaan pasar media. Termasuk diantaranya implikasi normatif untuk pembuatan kebijakan dan regulasi dalam industri media. SPC dinamika industri media pada umumnya secara umum bisa dilihat melalui Industrial Organization Model sebagai berikut :

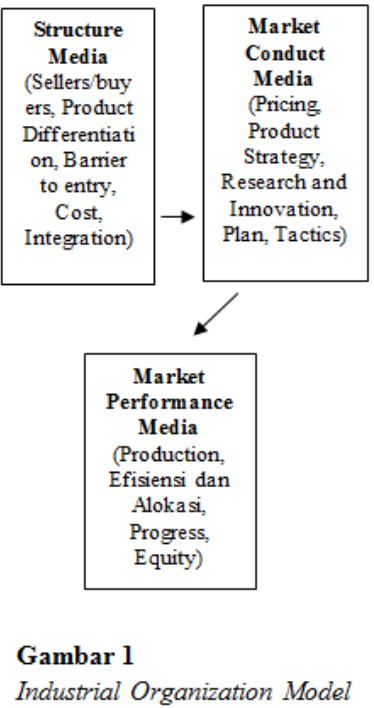

\section{Strategi Integrasi}

Menurut (Rangkuti, 2013) strategi adalah alat untuk mencapai tujuan. Dengan kata lain, strategi adalah kegiatan yang terus menerus dilakukan dan memerlukan kompetensi inti untuk mencapainya. Richard L Daft mendefenisikan strategi sebagai rencana tindakan yang menggambarkan alokasi sumber daya dan kegiatan lainnya dalam menghadapi lingkungan dan mencapai tujuan organisasi. Dalam membangun strategi yang kukuh hal yang pertama dilakukan adalah perusahaan harus mampu melihat pasar secara kreatif dan membagi-bagi pasar tersebut ke dalam berbagai segmen.

Integrasi pada media menurut (Susanto, 2017) dapat terjadi dalam proses vertikal ataupun horizontal. Kedua jenis integrasi ini, lazim terjadi melalui proses mekanisme merger dan take over. Integrasi horizontal terjadi ketika suatu kelompok bisnis memperoleh unit tambahan dalam tingkat produksi yang sama, dan memungkinkan perusahaan melakukan konsolidasi dan memperluas kontrol terhadap lini produksi yang sama. Sementara itu, integrasi vertikal adalah terjadi ketika kelompok bisnis melakukan ekpansi terhadap kelompok bisnis dengan tahapan produksi yang berbeda. Integrasi vertikal memungkinkan satu perusahaan memperluas kontrol terhadap tahapan 
produksi sehingga pada titik ekstrimnya adalah penguasaan proses produksi dari hilir ke hulu. Pemusatan media telah memengaruhi hubungan antara beberapa jenis organisasi media dengan satu orang konglomerat di dalamnya.

\section{Efisiensi}

Dalam kajian ekonomi politik media alasan lain terpusatnya kepemilikan media adalah efisisensi. Kelompok media selain melakukan integrasi horizontal, juga melakukan integrasi vertikal (Karman, 2014). Salah satu upaya yang dilakukan media saat ini adalah dengan pemanfaatan integrasi media untuk dapat melakukan efisiensi yang berpengaruh terhadap daya saing media tersebut dalam persaingan industri media. Efisiensi dapat dilakukan terhadap proses produksi maupun distribusi konten media yang dapat dilakukan dalam waktu yang cepat dan struktur organisasi yang semakin ramping.

Efisiensi produksi adalah salah satu cara dalam bentuk usaha yang dilakukan dalam menjalankan ssesuatu strategi dengan baik, tepat guna dan waktu, serta meminimalisir biaya untuk menghindari pemborosan sumber daya yang digunakan. Efisiensi berkaitan dengan masalah biaya seperti fungsi biaya, karakteristik biaya, dan hal - hal yang berkaitan dengan biaya.

\section{Kompetisi Media}

Mencermati kompetisi media massa dapat dikaji dengan teori Niche (Niche dapat diartikan sebagai celung atau ruang kehidupan). Teori Niche bertitik tolak dari pandangan ekologis dalam melihat persaingan antar media. Ibaratnya proses kompetisi antar industri media ini sebagai proses ekologis atau bioecology /humanecology yang melihat kemampuan media untuk memberikan kompetensi pada jalur distribusi produk di pasar penyiaran, dan progressnya (Khadziq, 2016)

Lazimnya, kompetisi antar media mulai terlihat pada saat munculnya media baru karena saat itu kompetisi memperebutkan khalayak. Persoalan paling penting dalam kompetisi media adalah melihat equity (kemampuan bersaing dalam distribusi produk), dan progres yang berjalan.
Melihat lebih jauh kompetisi antar media, John Dimmick dan Erick Rothenbuhler menggunakan pendekatan kompetisi media untuk mempertahankan kehidupannya dengan selalu berusaha mendapatkan sumber penunjang yang cukup. Sedangkan kenyataannya, sumber penunjang tersebut jumlahnya terbatas dan diperebutkan oleh media yang terus bertambah jumlahnya. Adapun sumber penunjang media adalah: Capital (pemasukan iklan, omzet, sirkulasi), content (isi), audience (khalayak sasaran).

\section{Pasar Industri Media}

Dalam teori pasar dan kepemilikan media, menjelaskan bahwa "market competition creates an incentive for a market enterprise (e.g. capital holder) to gain power in relation to other resource owners (e.g. labor or other competitors) as much as it creates an incentive to produce goods efficiently". Dengan kata lain kompetisi pasar telah menciptakan insentif bagi pemilik modal untuk mendapatkan kekuasaaan yang berhubungan dengan sumberdaya pemiliknya. Kompetisi pasar ini sekaligus menciptakan produksi barang/produk media secara efisien.

$(\mathrm{Fu}, 2003)$ mengemukakan tiga kerangka analisis yang dapat menjelaskan berbagai sisi kerja bisnis media. Ketiga kerangka tersebut sekaligus merupakan indikator yang cukup relevan untuk menilai karakteristik industri media karena menyajikan informasi pokok terkait dengan keunikan operasi bisnis media massa. Ketiga kerangka analisis yang dimaksud meliputi struktur ekonomi (structure), operasionalisasi perusahaan (conduct), dan kinerja perusahaan (performance)

\section{Industri Bisnis Media Penyiaran}

Institusi bisnis media massa penyiaran terdiri dari perusahaan media (media firm) dan industri media. (Mosco, 2009) mengatakan sebagai institusi bisnis media massa penyiaran melakukan proses ekonomi yaitu melakukan transaksi di pasar media, tarik menarik antara volume kualitas supply demand menjadi inti bisnis industri media sebagaimana komoditas lain.(Curran, Iyengar, Brink Lund, \& 
Salovaara-Moring, 2009): media as political and economic vehicle, tend to be controlled by conglomerates and media barons who are becoming fewer in number but though aquisition, controlled the larger mass media and communication.

Konsentrasi kepemilikan media mengacu pada pandangan bahwa mayoritas media besar memiliki sejumlah kecil pemilik (owner) perusahaan secara proporsional melalui sistem konglomerasi dalam korporasi (Azwar, 2017). Bahkan konsentrasi media ini menjadi sangat sulit dan tidak bisa dihindarkan karena dengan penyatuan kepemilikan media itu dapat menjadikan operasional industri lebih efisien.

\section{METODE PENELITIAN}

Dalam penelitian ini, paradigma yang digunakan adalah post-positivisme. Post-positivisme merupakan pemikiran yang menggugat asumsi dan kebenarankebenaran positivisme. Beberapa asumsi dasar post-positivisme adalah pertama, fakta tidak bebas melainkan bermuatan teori. Kedua, falibilitas teori. Tidak satu teori pun yang dapat sepenuhnya dijelaskan dengan bukti-bukti empiris yang memungkinkan untuk menunjukkan fakta anomali. Ketiga, fakta tidak bebas melainkan penuh dengan nilai. Keempat, interaksi antara subjek dan objek penelitian (Ardianto, 2011).

Hal ini menjelaskan bahwa paradigma post-positivisme berlawanan dengan paradigma positivisme, dimana positivisme melakukan penelitian dengan menggunakan data lapangan saja. Lain halnya dengan post-positivisme yang membutuhkan data lainnya agar memperkuat bukti-bukti empiris seperti wawancara dan keterkatitan dengan teori.

Penelitian ini menggunakan pendekatan kualitatif. Secara umum penelitian ini dilakukan untuk melihat bagaimana mengelola sebuah perusahaan media di era sekarang ini, secara khusus melihat integrasi MNC Group dalam meningkatkan efisiensi dan kompetisi di pasar industri media penyiaran. Penelitian kualitatif digolongkan dalam paradigma subjektif, reflektif atau interpretif yang berbeda dalam penelitian kuantitatif yang objektif. Lincoln (dalam (Albarran, 2004) menjelaskan penelitian kualitatif sebagai berikut :

“...is and interdisciplinary, and sometimes counterdicyplanary fields. It cross-cuts the humanitie, the social sciences. Qualitative research is many things at the time. It is multiparadigmatic in focus. Its practioners are sensitive to the value of the multimethod approach. They are commited to the naturalistic perspective and to interpretive understanding of human experience. At the same time, the field is inherently political and shaped by multiple ethical and political positions.

Peneliti menggunakan jenis penelitian deskriptif dengan pendekatan kualitatif. Penelitian deskriptif adalah penelitian yang memberikan gambaran suatu peristiwa dengan tidak mencari atau menghubungkan, tidak menguji hipotesis, dan tidak membuat prediksi (Mulyana \& Rakhmat, 2010). Penelitian deskriptif mengumpulkan data berupa kata-kata, gambar, dan tidak menggunakan angka (Moleong, 2017)

\section{PEMBAHASAN \\ Perilaku Media (Conduct MNC Media) di Pasar Industri Media Penyiaran}

\section{Pricing}

Pada prinsipnya, MNC media adalah industri penyiaran penyediaan konten, berupa paket informasi yang memperkaya intelektual, emosional, dan spritual konsumen.Tujuan dari produksi konten media adalah menarik perhatian konsumen untuk memaksimalkan pendapatan media.Penciptaan konten media dilakukan oleh pembuat film, penulis, jurnalis, musisi, para produser televisi dan radio.Untuk menciptakan kontent media, diperlukan faktor dan rantai nilai media yang membentuk pricing behaviour.

Bisnis media TV di MNC Media dapat dikategorikan menjadi bisnis kreatif. Isi (content) media pada umumnya adalah 
informasi yang dikemas dalam bentuk berita (news) hiburan (entertainment), maupun pendidikan (education), yang bermanfaat atau bernilai lebih dimata konsumen. Untuk dapat menciptakan informasi dengan kriteria tersebut, dibutuhkan kreativitas (creativity) dari pengelola media. Dalam kompetisi merebut pemasang iklan yang ditempuh melalui strategi pricing behaviour. Dalam menghadapi struktur pasar di Jakarta, MNC Media memiliki rate iklan yang cukup tinggi dan variatif dibandingkan stasiun - stasiun penyiaran.MNC Media mampu memberikan program - program siaran yang unik sehingga bisa dengan tepat menjangkau target listeners yang dituju yaitu kelas SES ABC dengan varian karakter televisi yang ada.

Analisa pricing pada MNC Media dimaksudkan sebagai sebuah strategi atau program untuk menciptakan bentuk yang tepat dalam mengelola harga produksi. Pricing dilakukan dengan mengklasifikasikan jenis beserta besaran pengeluaran untuk mendukung industri media diantaranya adalah cost structure yang terdiri dari fixed cost dan variabel cost. Fixed cost adalah pengeluaran dalam skala besar dan cenderung pasti dan tetap. Pengeluaran industri media televisi MNC Media sangat besar jika harus dibandingkan dengan industri media lainnya cetak atau radio di MNC Group dalam memproduksi programnya. Sedangkan variabel cost adalah pengeluaran yang dipergunakan MNC Media untuk aktivitas public relation, promotion, dan pengeluaran tak terduga dalam produksi.

\section{Product}

Dalam perilakunya, MNC Media memperkenalkan differensiasi produk untuk menggambarkan variasi produk yang dihasilkan media yang dimilikinya. Setiap unit media pada umumnya, televisi khususnya berusaha memiliki tingkat derajat differensiasi yang tinggi atas produk dan jasa yang mereka hasilkan agar mereka memiliki monopoli power. Hal ini bukan hanya menimbang kompetisi yang terjadi dengan grup media lain, namun juga terciptanya pilihan bagi pengiklan sebagai omset utama untuk beriklan dalam pilihan yang variatif.

Perkembangan MNC grup memiliki keragaman format program, format musik, gaya siaran, berita, pencitraan, marketing, dan fasilitas teknis yang dibuat berbeda segmen dan kelas antara TV satu dan lainnya. Keberagaman atau variasi ini terjadi untuk menghindari persaingan secara langsung atau head to head yang dihadapi oleh pengelola media dalam situasi pasar yang homogeny terutama dalam satu grup. Adanya variasi ini merupakan strategi pasar oligopoly untuk bersaing dalam memenuhi selera konsumen yang heterogen. Dengan kata lain, keberagaman muncul akibat beragamnya perusahaan yang ada.

\section{Strategy}

Strategi yang dilakukan oleh MNC Grup diperkuat dan dibenarkan dengan hukum yang dimiliki oleh MNC Group terkait dengan kerjasama, akuisisi, merger yang dilakukan. Dalam menjalankan kegiatan bisnisnya, MNC Group banyak melakukan strategi dengan melakukan akuisisi terhadap perusahaan-perusahaan sejenis. Misalnya adalah saat MNC Group melakukan akusisi terhadap TPI(MNCTV) dan Global TV. MNC Group juga menerapkan strategi pengembangan. Contohnya adalah MNC Group melakukan akuisisi terhadap perusahaan-perusahaan yang berbeda bidang industri dengan inti bisnis MNC Group.

Legal Tactics yang dilakukan MNC terjadi karena adanya kebutuhan kerja sama yang saling menguntungkan, dimana salah satu program membutuhkan media untuk berpromosi sedangkan sebaliknya, unit bisnis pendukung membutuhkan wadah untuk menempatkan produk atau artis sebagai content dalam medianya. Kerja sama juga biasanya dilakukan dalam program off-air. Hal ini melibatkan bisnis pendukung non brodcast seperti jasa keuangan, dan properti.

Setelah memiliki kekuatan secara hukum, strategi produk merupakan upaya masing - masing stasiun TV MNC Grup untuk menghasilkan format acara yang 
berbeda satu dan lainnya, termasuk dengan kompetitor. Dengan kata lain strategi program adalah upaya untuk masing masing stasiun televisi dalam mengembangkan program - programnya seoptimal mungkin. Terdapat tiga tahapan untuk melakukan strategi program, yaitu mendefinisikan khalayak potensial, menempatkan acara program di waktu yang tepat, dan menjaga loyalitas khalayak. Langkah dalam strategi selanjutnya adalah menentukan program di waktu yang tepat. Untuk pemilihan program stasiun televisi termasuk juga pemilihan talent atau penyiar yang menempati siapa yang bersiaran di program tersebut sangat perlu diperhatikan agar tidak terjadi perebutan pasar. Penentuan kesuksesan programming dalam penjadwalan dan talent dalam sebuah program televisi tidak terlepas dari sumber daya manusia yang kreatif dan inovatif. Perhitungan rating dan share sebuah program, peningkatan tersebut akan berjalan lurus dengan peningkatan harga slot iklan dalam program tersebut.

Selain product strategy, ada juga marketing advertising strategy yang memegang peranan penting dalam kesuksesan sebua hgrup media. Melalui marketing advertising masing-masing stasiun TV di MNC Grup bersaing secara sehat untuk mendapatkan perhatian sebanyak-banyaknya dan saling membantu mereka dalam merebut pemasang iklan.

\section{Development}

Layaknya mesin sebuah perusahaan, sumber daya adalah hal pertama yang sangat penting diperhatikan dalam perkembangan dan pertumbuhan MNC Media kearah yang lebih baik. Sumber daya disini dapat dibagi antara sumber daya manusia (karyawan) sumber daya mekanis (alat). MNC telah mempersiapkan seutuhnya sistem development yang baik pada kedua jenis sumber daya tersebut untuk menciptakan fungsi kerja yang optimal.

Selain itu, dalam mendukung kerja media grup dibutuhkan investasi usaha terkait dengan perangkat yang ada. Perangkat dalam stasiun televisi sebagai bisnis utama yang menjadi investasi mahal dan menjadi perangkat pendukung yang sangat vital adalah transmisi dan satelit. Pemancar berfungsi dalam mengukur coverage targetnya MNC Media yang berada hampir di seluruh wilayah Indonesia. Jangkauan frekuensi berfungsi juga untuk kelancaran perkembangan usaha seperti masalah sinyalnya. Hal ini tentu saja perlu mempertimbangkan besaran biaya teknis sebuah televisi media grup.

Berikutnya, pelatihan tertentu juga dilaksanakan untuk masing-masing kebutuhan pengembangan kompetensi karyawan, seperti manager forum, leadership, bahkan program-program lainnya.

\section{Innovation}

Untuk berjalannya semua strategi integrasi media dengan baik, sebuah perusahaan group media terlebih dahulu wajib melakukan penelitian awal (research) untuk mengetahui kemampuan, kebutuhan pasar, dan rencana. Riset tersebut juga membantu strategi $\mathrm{MNC}$ Grup untuk melakukan inovasi yang perlu mereka lakukan. Saat ini, demi mendukung pangsa pasar yang lebih besar, MNC Grup memberikan inovasi dalam produk dan program yang dimiliki dengan bersinergi antara aktivitas free to air televisi yang dimiliki dengan kemampuan internet online, TV berlangganan. Selain itu, inovasi yang terbaru adalah kemampuan fiber optic MNC Play Media. Hal ini cukup memberikan terobosan terbaru dalam sejarah perkembangan industri televisi dan internet di Indonesia.

\section{Perform Media (Efisiensi dan Kompetisi MNC Media) di Pasar Industri Media Penyiaran}

\section{Efisiensi}

Berdasarkan pembahasan market conduct yang telah dilakukan MNC Media Group dalam menghadapi market structure persaingan industri radio di Jakarta, pembahasan dalam performance (kinerja media) ini akan melihat sejauh mana performance yang telah dilakukan MNC 
Media untuk mencapai target. Performance MNC Media dalam hal ini akan dibahas berdasarkan; product efficiency, allocative efficiency dengan masing-masing mempertimbangkan efisiensi ekonomis dan teknisnya

\section{a. Product Efficiency}

Product efficiency adalah bentuk performance industri media grup dalam menghasilkan sebuah program dengan seefisien mungkin. Di MNC Media, dikatakan bahwa pimpinan atau manajer menjadi kunci utama keberhasilan dalam proses transformasi sekaligus menjadi pengawas untuk karyawannya. Dengan ketatnya persaingan di bisnis media yang dituntut untuk dinamis setiap waktunya, maka proses kreatifitas dan keputusan keputusan yang penting tidak bisa menunggu jalur birokrasi yang panjang. MNC Media cukup banyak melakukan pemangkasan dari berbagai segi. Misal, karyawan, dan peralatan teknis.

\section{b. Allocative Efficiency}

Allocative Efficiency merupakan tolak ukur performance MNC Media dalam ketepatan penggunaan sumber daya yang tersedia sehingga dapat dialokasikan secara optimal. MNC Group sangat ketat dalam efisiensi sumberdaya yang dimilikinya. MNC Media memberikan pelatihan kepada setiap divisinya sehingga bisa memahami standarisasi untuk penekanan cost.

\section{Kompetisi}

Berdasarkan efisiensi media perform MNC Media Grup yang sudah dibahas sebelumnya dalam menghadapi market structure persaingan industri media grup di Iakarta, pembahasan dalam market performance kompetisi ini akan melihat sejauh mana kompetisi yang telah dilakukan MNC Media untuk mendapatkan target audience dan pemasang iklan berdasarkan progress dan equity. Dalam progressnya, peningkatan posisi dalam pasar industri media penyiaran khususnya televisi, berdasarkan peningkatan rating share dan revenue.
Bila melihat progressnya sebagai grup media terbesar di Jakarta, sampai saat ini MNC Group masih menduduki strategi peringkat terorganisir dalam rating dan share jumlah penonton. Idealnya, RCTI selalu berada di posisi pertama, MNCTV keempat atau kelima, GlobalTV di posisi ke tujuh. Sehingga MNC Media masih mampu mempertahankan posisinya sebagai market leader dalam pasar industri media televisi di Jakarta, tentunya dengan progress yang meningkat seiring dengan meningkatnya berbagai persaingan dengan televisi lain.

Dalam studi kasus MNC Media Grup, meskipun masing-masing stasiun televisi mempunyai rate card yang berbeda-beda dan cenderung tinggi dibandingkan dengan kompetitornya, tapi MNC Media tetap memberikan penawaran yang cukup negotiable dari harga normal sebagai konsekuensinya. Atau dalam bentuk paket jualan. Jika MNC Media tidak melakukan hal tersebut, tentunya ada kemungkinan besar akan ditinggalkan oleh agensi atau pengiklan rekanannya. Hal tersebut disebabkan pengiklan akan memperhitungkan kembali efisiensi pemasangan iklan distasiun televisi di bawah MNC Media. Jika tidak efisien, maka tentunya pengiklan akan mencari stasiun lain yang mampu memberikan rate card yang lebih efisien.

\section{PENUTUP}

Integrasi media sebagai kegiatan aktivitas sinergi di bidang media, atau aktivitas manajemen media yang dikelola satu kepemilikan untuk kepentingan efisiensi ekonomis dan teknik pengelolaan media tersebut sehingga mampu berkompetisi dengan media kompetitor. Hal ini sangat bergantung dengan bagaimana media memproduksi informasi (media content) untuk memuaskan audience, pemasang iklan dan masyarakat dengan menggunakan sumber daya yang tersedia. Berdasarkan analisis yang telah dilakukan dapat diambil beberapa kesimpulan.

Integrasi secara horizonal dan vertikal, merupaka faktor utama yang menjadi keberhasilan MNC Grup dalam industri media televisi di Indonesia tidak 
lepas dari visi dan misi MNC Grup untuk menjadi media dengan kekuatan sinergi antara pilar utama bisnisnya yaitu televisi dan lini pendukung bisnis yang menjadi landasan mereka dalam menciptakan dan mempertahankan eksistensinya.

1. Pertama, jelas MNC Media hadir sebagai media grup yang memiliki kekuatan besar dengan keunggulan structure media yang berkaitan dengan perilaku (conduct) sebuah media yaitu product, pricing, strategy, development dan innovation sebuah perusahaan media baru dengan cepat, sehingga menjadi market leader di Indonesia. Proses riset awal MNC Media menghasilkan data bahwa integrasi memang dilaksanakan dan dipantau dengan teliti untuk mempertimbangkan penggunaan sumber daya dengan tepat dan hasil yang maksimal.

2. Kedua, komparasi pertimbangan product differentiation, konsumen, cost structures, vertical integration, dan horizontal integration sebagai market structure yang dihadapi oleh MNC Media dalam industri televisi saat ini dengan adanya pricing behavior dengan dibuatnya konsep limited space dalam penjualan iklan. Dengan adanya konsep limited space ini maka bisa dilakukan servis yang ekslusif terhadap klien dengan tidak mengabaikan kenyamanan penonton karena banyaknya iklan di televisi.

3. Ketiga, manajemen cash flow yang baik dari perusahaan production efficiency, allocative efficiency, progress dan equity sebagai tolak ukur market performance efisiensi dan kompetisi MNC Media berdasarkan market conducts yang telah dilakukan sampai saat ini. Keberhasilan usaha secara bisnis, pada hakikatnya adalah keberhasilan dari bisnis dimana investasi itu dilaksanakan. Suatu bisnis dikatakan berhasil bila mendapat laba karena laba adalah tujuan dari sebuah perusahaan melakukan bisnis salah satunya efisiensi. Tidak dijelaskan secara detail mengenai data keuangan MNC Media karena datanya sangat confidential, namun dari keterangan yang ada, menyatakan bahwa jika dihitung dari total investasinya, MNC Media telah mengalami Break Even Point (BEP).

4. Keempat, dengan riset dan inovasi untuk kepentingan kompetisi yang kuat, semua bekerja bukan berdasarkan asumsi dan program manajer semata untuk membuat sesuatu tetapi juga berdasarkan kemauan penonton dan pengiklan. Sistem yang dilakukan MNC Media secara komersial sebagai dual market semuanya bekerja berdasarkan survey yang sudah dibuat. Dari hasil riset dan inovasi inilah akhirnya MNC Media mempunyai kekuatan dan differensiasi produk diantara satu televisi dan televisi lainnya dibandingkan dengan grup media lain yang kuran terpola dalam khalayak sehingga cenderung terjadi pertempuran antara satu grup televisi. MNC Media akhirnya dapat memberikan servis terbaiknya terhadap konsep dual market industri media khususnya dalam berkompetisi.

\section{REFERENSI}

Albarran, A. B. (2004). Media economics. In The SAGE Handbook of Media Studies. https://doi.org/10.4135/97814129760 77.n15

Ardianto, E. (2011). Analisis Wacana Kritis Pemberitaan Harian Pikiran Rakyat Dan Harian Kompas Sebagai Politik Dalam Membentuk Presiden Susilo Bambang Yudhoyono (Sby). Ilmu Komunikasi. https://doi.org/10.1002/97811192085 01.ch9 
Azwar, A.-. (2017). INDUSTRI

TELEVISI DAN WAJAH BURAM

POLITIK INDONESIA. Jurnal

Komunika : Jurnal Komunikasi,

Media Dan Informatika.

https://doi.org/10.31504/komunika.v6 i2.1109

Curran, J., Iyengar, S., Brink Lund, A., \& Salovaara-Moring, I. (2009). Media system, public knowledge and democracy: A comparative study. European Journal of Communication. https://doi.org/10.1177/02673231080 98943

$\mathrm{Fu}, \mathrm{W}$. (2003). Applying the structure-conduct-performance framework in the media industry analysis. International Journal on Media Management. https://doi.org/10.1080/14241270309 390043

Karman. (2014). MONOPOLI

KEPEMILIKAN MEDIA \&amp; LENYAPNYA HAK PUBLIK. Jurnal Masyarakat Telematika Dan Informasi.

Khadziq, K. (2016). KONVERGENSI MEDIA SURAT KABAR LOKAL (Studi Deskriptif Pemanfaatan Internet Pada Koran Tribun Jogja dalam Membangun Industri Media Cetak Lokal). Profetik: Jurnal Komunikasi. https://doi.org/10.14421/pjk.v9i1.118 7

Moleong, L. J. (2017). Metodologi Penelitian Kualitatif (Edisi Revisi). In PT. Remaja Rosda Karya.

Mosco, V. (2009). The political economy of communication. In The Political Economy of Communication. https://doi.org/10.4135/97814462799 46

Mulyana, D., \& Rakhmat, J. (2010). Komunikasi antarbudaya. In Penantar Komunikasi antarbudaya. Rangkuti, F. (2013). Teknik Membedah Kasus Bisnis Analisis SWOT Cara Perhitungan Bobot, Rating, dan OCAI. In PT. Gramedia Pustaka Utama. Jakarta.

Rusadi, U. (2018). TALK SHOWISU PUBLIK DI TELEVISI DAN DINAMIKA DEMOKRASI. Jurnal
Studi Komunikasi Dan Media. https://doi.org/10.31445/jskm.2012.1 60105

Susanto, E. H. (2017). MEDIA SOSIAL SEBAGAI PENDUKUNG JARINGAN KOMUNIKASI POLITIK. Jurnal ASPIKOM. https://doi.org/10.24329/aspikom.v3i 3.123

\section{BIODATA PENULIS}

Geofakta Razali, lulusan Magister Ilmu (M.I.Kom) Program Pasca Sarjana Universitas Budi Luhur Jakarta tahun 2017 dan lulusan Ilmu Komunikasi (S.I.Kom) Universitas Riau tahun 2013. Saat ini mahasiswa Doktoral Komunikasi 